\title{
Implementation Possibilities of SMD Capacitors for High Power Applications
}

\author{
Janis Zakis (Senior Research Fellow, Tallinn University of Technology), \\ Dmitri Vinnikov (Principal Research Fellow, Tallinn University of Technology)
}

\begin{abstract}
Focus is on implementation possibilities of surfacemount device (SMD) to be used in high power applications. SMD capacitors reduce the size and dimensions of a power circuit and increase the flexibility of placement of other components. Ceramic and electrolytic capacitors are compared by means of voltage ripple, volume, labour-intensity and impedance. A 1 kW experimental setup of a quasi-Z-Source inverter (qZSI) based converter was built to compare SMD capacitor performance in the quasi-Z-source (qZS) network.
\end{abstract}

Keywords - Power conditioning, switched-mode power supply, power capacitors, surface-mount technology.

\section{INTRODUCTION}

Capacitors are one of the basic passive elements in different electric circuits. Today's types of capacitors offered in the market are varied, optimized for different kinds of applications. Also, the range of choices for capacity and operation voltage is very wide.

The field of power electronics cannot be imagined without capacitors that limit the growth of voltage (voltage ripple). Operation voltage is always the limiting factor for a capacitor and accordingly for the dimensions of the whole system. Usually for the same size of a capacitor, the smaller the capacity, the higher is the operation voltage of a capacitor. Since this fact is significant, for it affects the power density and dimensions of the whole system $[1,2]$, it was decided to use SMD capacitors in the power circuit.

The aim of this paper is to implement and compare different types of SMD capacitors available in the market for a $1 \mathrm{~kW}$ quasi-Z-source inverter (qZSI) based step-up converter (Fig.1.) $[3,4]$. To provide $1.4 \%$ voltage ripple on a DC-link the capacitance of capacitors should be $220 \mu \mathrm{F}$. Since the rated voltage of the DC-link is $80 \mathrm{~V}$, capacitors of at least $100 \mathrm{~V}$ should be selected.

\section{IDEA OF EXPERIMENT}

\section{A. Experimental Setup}

The circuit diagram in Fig. 1 consists of a VSI coupled with a qZS-network $\left(C_{1}, C_{2}, L_{1}, L_{2}, D\right)$. Based on the input voltage, the operating modes of the proposed DC/DC converter could be broadly categorized as non-shoot-through and shootthrough operating modes $[3,4]$. If the input voltage is equal or higher than the desired DC-link voltage, the converter works in the non-shoot-through mode. In this mode, the qZSI operates as a traditional VSI, performing only the buck function of the input voltage.

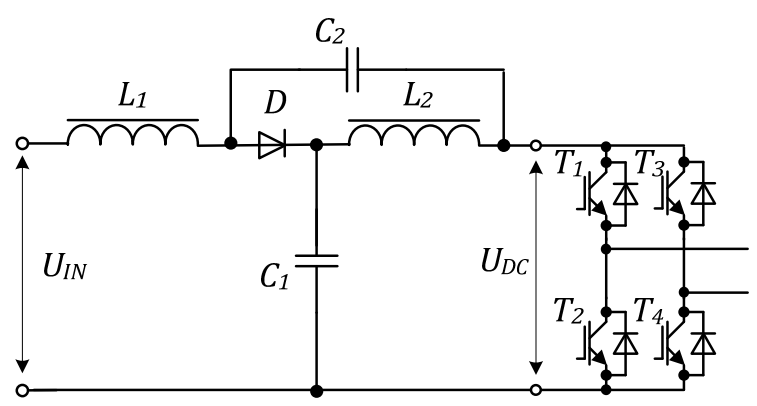

Fig. 1. General circuit diagram used in the experiments.

The operating period of the qZSI in the non-shoot-through operating mode consists of the combination of active and zero states, explained in detail in [4].

If the input voltage drops below the predefined DC-link voltage level, the converter starts to operate in the shootthrough mode. During the shoot-through states the upper and lower switches of one or both phase legs are conducting (i.e., both devices are conducting) [3, 4].

In general, each operating period of the qZSI during the shoot-through mode always consists of an active state $t_{A}$, a shoot-through state $t_{\mathrm{S}}$ and a zero state $t_{\mathrm{Z}}$ :

$$
\begin{gathered}
T=t_{A}+t_{S}+t_{Z} \\
\frac{t_{A}}{T}+\frac{t_{S}}{T}+\frac{t_{Z}}{T}=D_{A}+D_{S}+D_{Z}=1
\end{gathered}
$$

where $D_{A}$ is the duty cycle of an active state, $D_{S}$ is the duty cycle of a shoot-through state and $D_{Z}$ is the duty cycle of a zero state.

Table I shows general operation and component ratings.

TABLE I

GENERAL OPERATION AND COMPONENT RATINGS

\begin{tabular}{|l|l|}
\hline Parameter & Value \\
\hline Minimal input voltage, $U_{I N(\min )}$ & $40 \mathrm{~V}$ \\
\hline Nominal input voltage, $U_{I N(\text { nom })}$ & $80 \mathrm{~V}$ \\
\hline Desired DC-link voltage, $U_{D C}$ & $80 \mathrm{~V}$ \\
\hline System power rating, $P$ & $1000 \mathrm{~W}$ \\
\hline Operation frequency of a qZS-network, $f_{q z S}$ & $60000 \mathrm{~Hz}$ \\
\hline Desired voltage ripple across the DC-link & $1.4 \%$ \\
\hline Inductance of inductors $L_{1}, L_{2}$ & $50 \mu \mathrm{H}$ \\
\hline
\end{tabular}




\section{B. Capacitor Parameter Calculations}

At the steady state the average voltage of the capacitors can be calculated as follows:

$$
U_{C 1}=\frac{1-D_{S}}{1-2 \cdot D_{S}} \cdot U_{I N}
$$

and

$$
U_{C 2}=\frac{D_{S}}{1-2 \cdot D_{S}} \cdot U_{I N}
$$

The DC-link voltage across the inverter bridge is the sum of both capacitor voltages, expressed as

$$
u_{D C}=U_{C 1}+U_{C 2}=\frac{1}{1-2 \cdot D_{S}} \cdot U_{I N}
$$

During the active state, both of the capacitors are connected in series and limit the voltage ripple on the DC-link [4]. It is assumed that the capacitances of the capacitors are equal and can be calculated as

$$
\begin{aligned}
& C=\frac{2 \cdot P \cdot D_{S}}{U_{I N} \cdot U_{D C} \cdot f \cdot r_{V, D C}}= \\
& =\frac{2 \cdot 1000 \cdot 0.25}{40 \cdot 80 \cdot 50000 \cdot 0.014} \approx 220 \mu \mathrm{F}
\end{aligned}
$$

where $P$ is the power rating of the converter, $U_{I N}$ is the input voltage, $U_{D C}$ is the DC-link voltage, $D_{S}$ is the duty cycle of shoot-through states, $f$ is the operation frequency of the qZSI, and $r_{V, D C}$ is the desired peak to peak voltage ripple across the DC-link.

\section{Capacitors Selected for Experiments}

According to operation voltage range $(100 \mathrm{~V})$ ceramic capacitor "Murata" (GRM32ER72A225K) [5] with a capacitance of $2.2 \mu \mathrm{F}$ and Aluminum electrolytic capacitor from "Panasonic" (EEEFK2A221AM) [6] with a capacitance of $220 \mu \mathrm{F}$ were selected for further study. Since the capacitance of a ceramic capacitor is $2.2 \mu \mathrm{F}$, they were soldered 100 in parallel to obtain $220 \mu \mathrm{F}$.

For experimental verification, two similar qZS-networks were built - with electrolytic capacitors and with ceramic capacitors. Fig. $2 a$ presents a PCB where 200 SMD capacitors are soldered to obtain the capacitance of $220 \mu \mathrm{F}$ per each qZSI capacitor $\left(C_{1}\right.$ and $\left.C_{2}\right)$. Each capacitor $\left(C_{1}\right.$ and $\left.C_{2}\right)$ consists of 100 SMD capacitors that are arranged in 33 columns. There are 3 SMD capacitors in one column. Such arrangement was selected in order to make more compact design. Fig. $2 b$ presents a PCB where two $220 \mu \mathrm{F}$ electrolytic capacitors $\left(C_{1}\right.$ and $C_{2}$ ) are used.
Foil capacitors were not selected because of their too small capacitance of $100 \mathrm{~V}$ and too high costs compared with electrolytic and ceramic capacitors (Fig. 3).

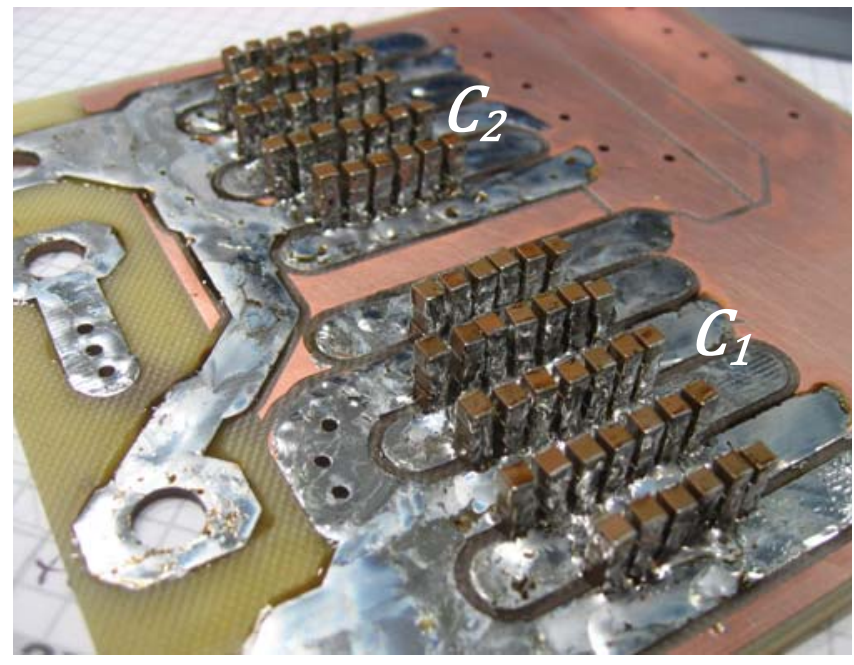

(a)

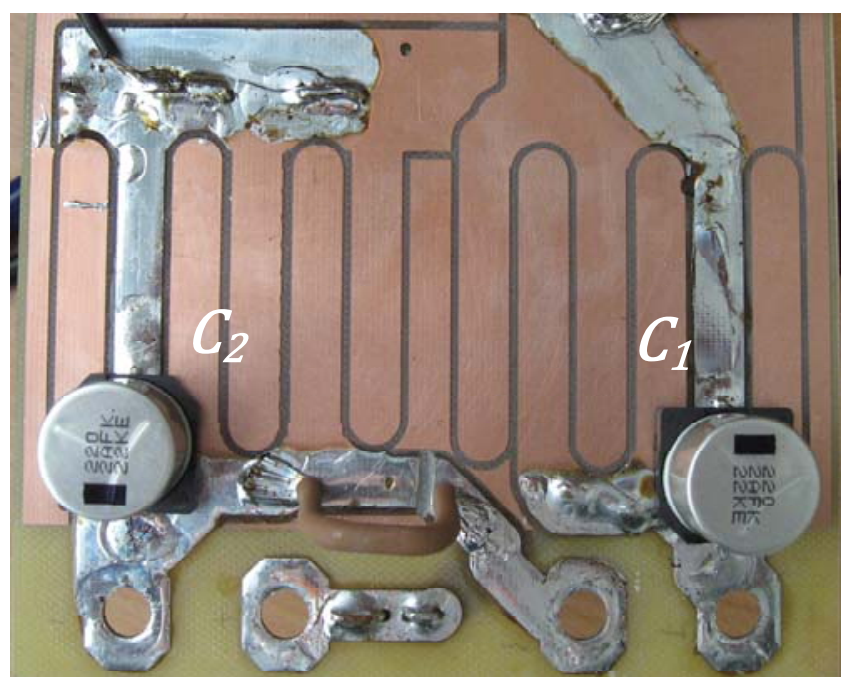

(b)

Fig. 2. Capacitances $C_{1}$ and $C_{2}$ that consist of 200 SMD capacitors (a) and electrolytic capacitors (b)

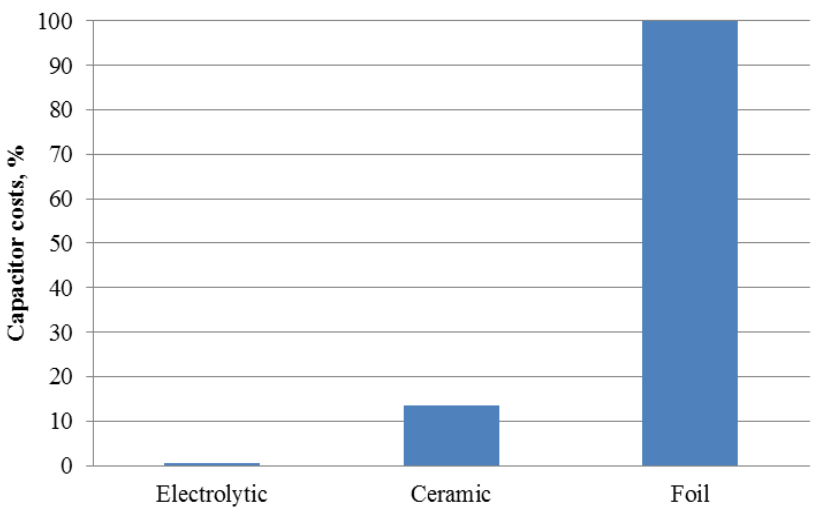

Fig. 3. Capacitor price comparison. 


\section{ANALYSIS OF EXPERIMENTAL RESULTS}

\section{A. General Operation Waveforms}

The experimental verification of both capacitor types were carried out at different operation points, i.e. the input voltage was changed from $U_{I N,(\text { min) }}(40 \mathrm{~V})$ up to $U_{I N,(\text { nom })}(80 \mathrm{~V})$ and $D_{S}$ was regulated so that the DC-link voltage remained at $80 \mathrm{~V}$.

Fig. 4 shows the input voltage $\left(U_{I N}\right)$, the DC-link voltage $\left(U_{D C}\right)$, the input current $\left(I_{I N}\right)$ and the DC-link current $\left(I_{D C}\right)$ of the converter operating with electrolytic (Fig. 4a) and ceramic (Fig. 4b) capacitors when the input voltage is at its rated value $(80 \mathrm{~V})$.

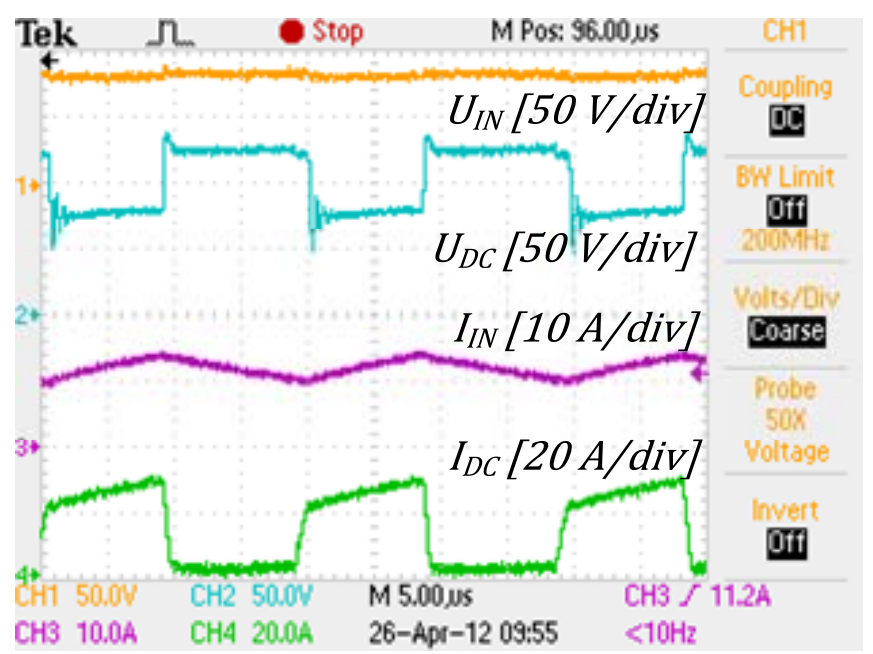

(a)
Fig. 5 presents the input voltage $\left(U_{I N}\right)$, the DC-link voltage $\left(U_{D C}\right)$, the input current $\left(I_{I N}\right)$ and the DC-link current $\left(I_{D C}\right)$ of the converter operating with electrolytic (Fig. 5a) and ceramic (Fig. $5 b$ ) capacitors when the input voltage is at its minimal value $(40 \mathrm{~V})$.

Fig. 6 shows the capacitor $C_{1}$ voltage $\left(U_{C 1}\right)$, the capacitor $C_{2}$ voltage $\left(U_{C 2}\right)$, the capacitor $C_{1}$ current $\left(I_{C 1}\right)$ and the capacitor $C_{2}$ current $\left(I_{C 2}\right)$ of the converter operating with electrolytic (Fig. 6a) and ceramic (Fig. 6b) capacitors when the input voltage is at its nominal value $(80 \mathrm{~V})$.

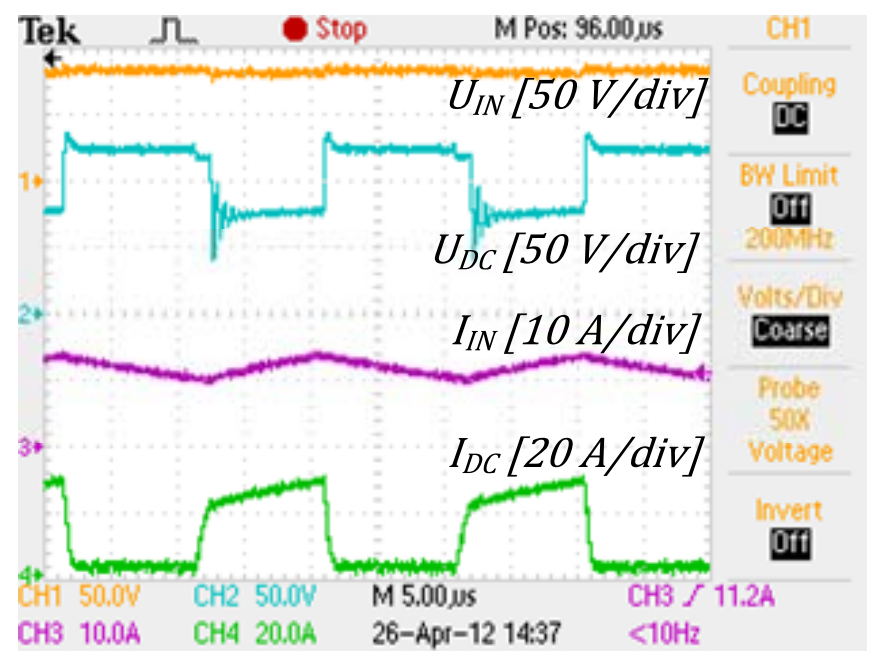

(b)

Fig. 4. Operation waveforms ( $\left.U_{I N}, U_{D C}, I_{I N}, I_{D C}\right)$ of a qZSI with electrolytic capacitors (a) and with ceramic capacitors (b) at $U_{I N}=80 \mathrm{~V}$.

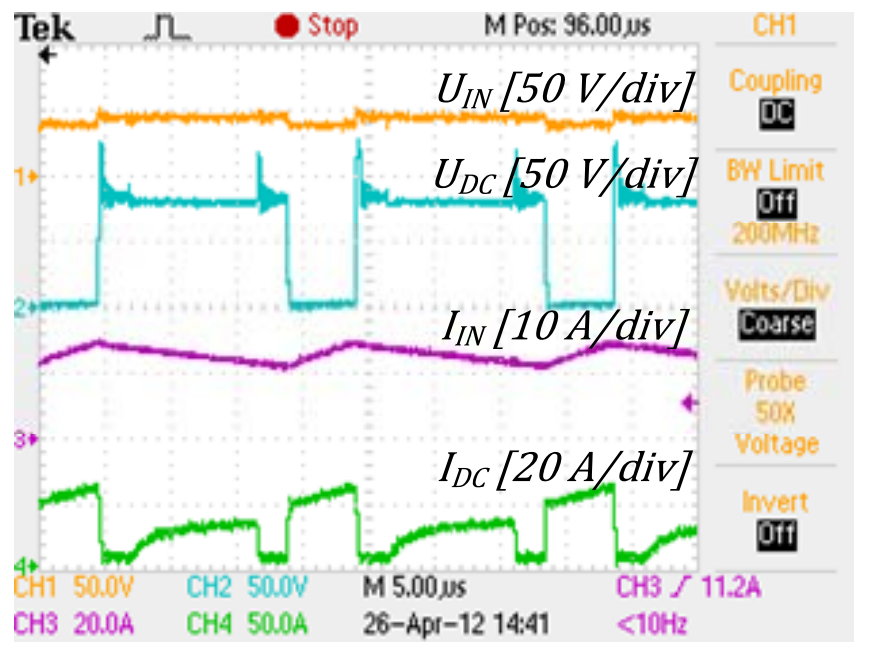

(a)

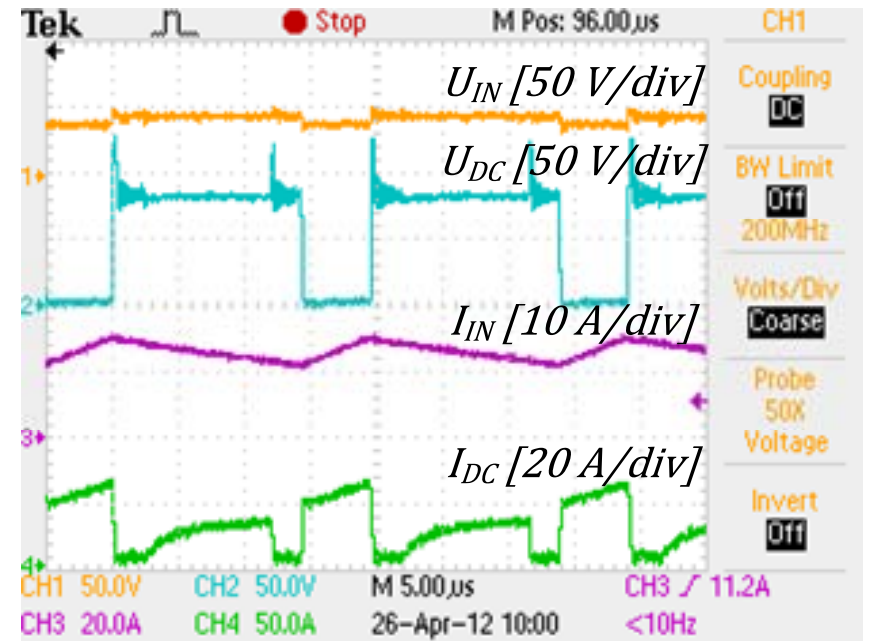

(b)

Fig. 5. Operation waveforms ( $\left.U_{I N}, U_{D C}, I_{I N}, I_{D C}\right)$ of a qZSI with electrolytic capacitors (a) and with ceramic capacitors (b) at $U_{I N}=40 \mathrm{~V}$. 


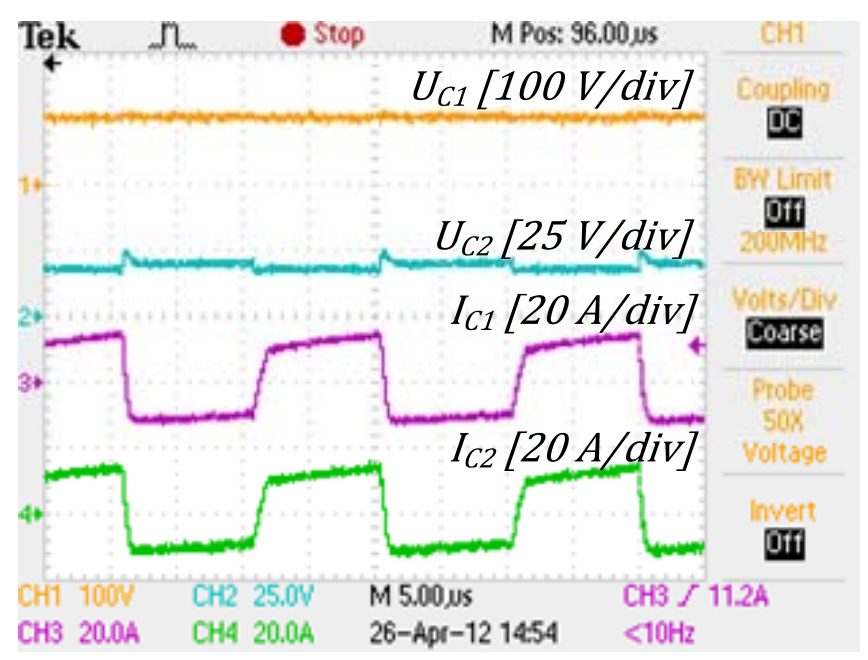

(a)

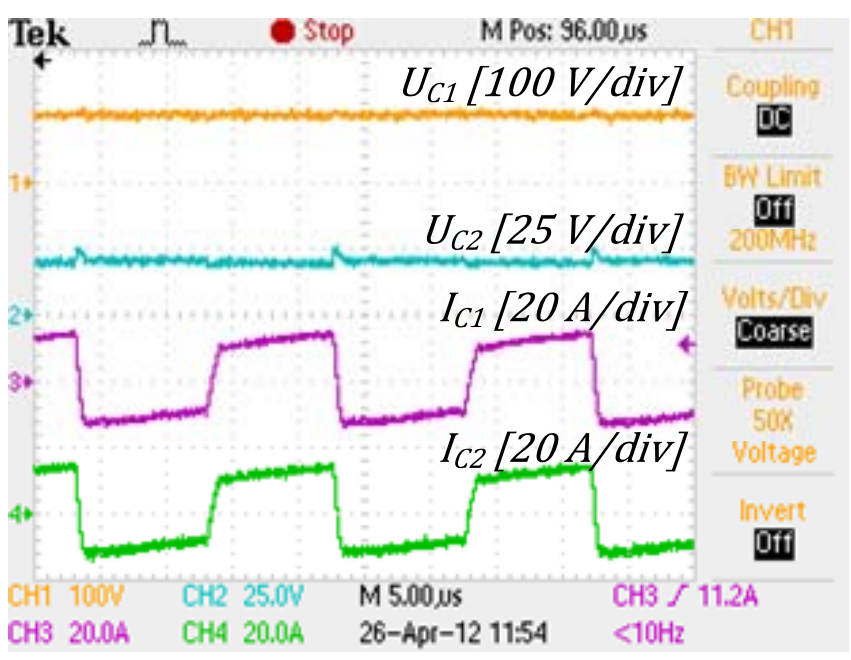

(b)

Fig. 6. Operation waveforms $\left(U_{C 1}, U_{C 2}, I_{C 1}, I_{C 2}\right)$ of a qZSI with electrolytic capacitors (a) and with ceramic capacitors (b) at $U_{I N}=80 \mathrm{~V}$.

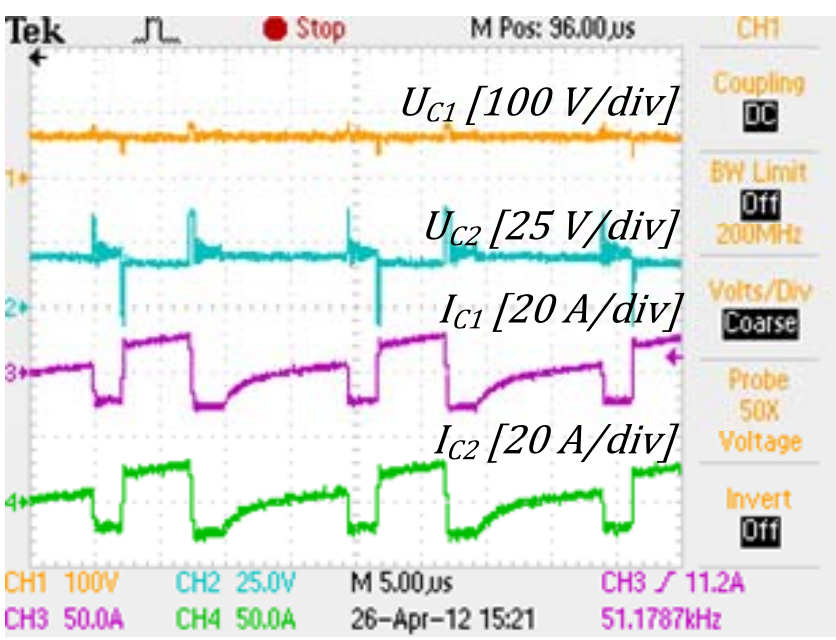

(a)

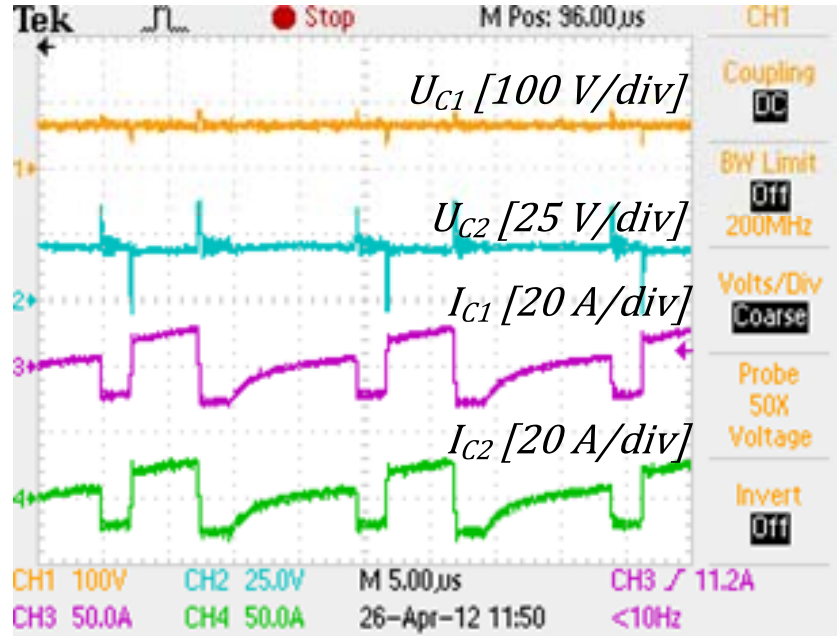

(b)

Fig. 7. Operation waveforms $\left(U_{C 1}, U_{C 2}, I_{C 1}, I_{C 2}\right)$ of a qZSI with electrolytic capacitors (a) and with ceramic capacitors (b) at $U_{I N}=40 \mathrm{~V}$.

Fig. 7 presents the capacitor $C_{1}$ voltage $\left(U_{C 1}\right)$, the capacitor $C_{2}$ voltage $\left(U_{C 2}\right)$, the capacitor $C_{1}$ current $\left(I_{C 1}\right)$ and the capacitor $C_{2}$ current $\left(I_{C 2}\right)$ of the converter operating with electrolytic (Fig. 7a) and ceramic (Fig. 7b) capacitors when the input voltage is at its minimal value $(40 \mathrm{~V})$.

\section{B. Voltage Ripple}

To prove capacitor performance in voltage ripple damping the capacitor voltage ripple of both qZSI capacitors $\left(C_{1}\right.$ and $C_{2}$ ) were examined separately.

Fig. 8 presents the voltage ripple of an electrolytic and a ceramic capacitor. It can be seen that the difference between the capacitor $C_{1}$ voltage ripple is greater in input voltage range from $40 \mathrm{~V}$ up to $60 \mathrm{~V}$ (Fig. 8a). In the input voltage range from $60 \mathrm{~V}$ up to $80 \mathrm{~V}$ the difference is negligible. Fig. $8 b$ shows that big difference in capacitor $C_{2}$ voltage ripple is in whole range of input voltage (from $40 \mathrm{~V}$ up to $80 \mathrm{~V}$ ).

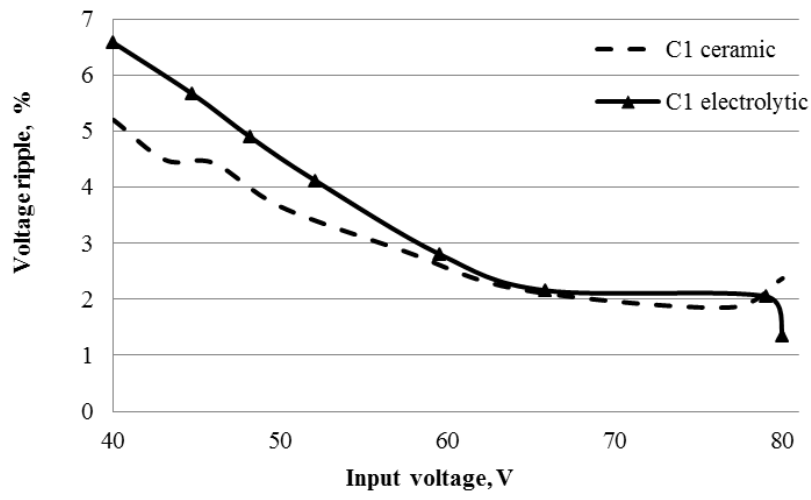

(a) 
$2012 / 1$

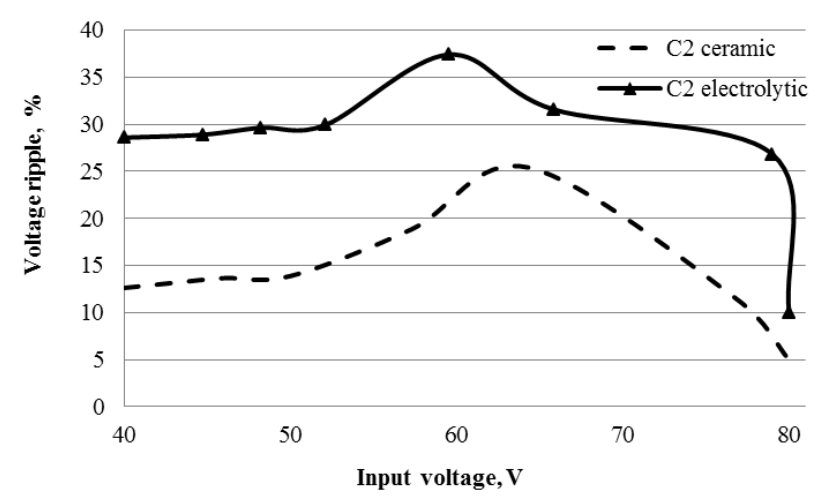

(b)

Fig. 8. Comparison of voltage ripple using ceramic and electrolytic capacitors: capacitor $C_{1}(\mathrm{a})$ and capacitor $C_{2}(\mathrm{~b})$.

Fig. 9 presents experimental and theoretical voltage ripple on the DC-link during the active state when capacitors $\left(C_{1}\right.$ and $C_{2}$ ) are in series. In the input voltage range up to $65 \mathrm{~V}$, the voltage ripple in both capacitor types is close to the theoretical curve. In the input voltage range from $65 \mathrm{~V}$ up to $80 \mathrm{~V}$, the measured and theoretical voltage ripples are not in agreement. These phenomena can be explained by the over-boost effect. It means that the qZS-network itself can cause an increase in the DC-link voltage.

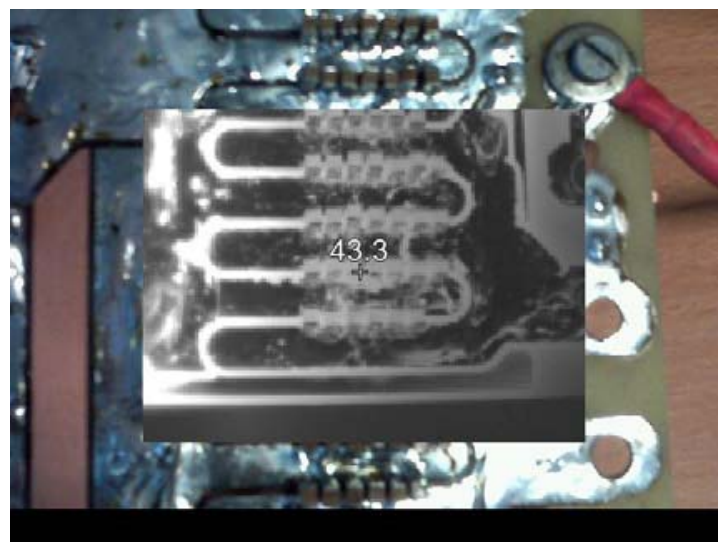

(a)

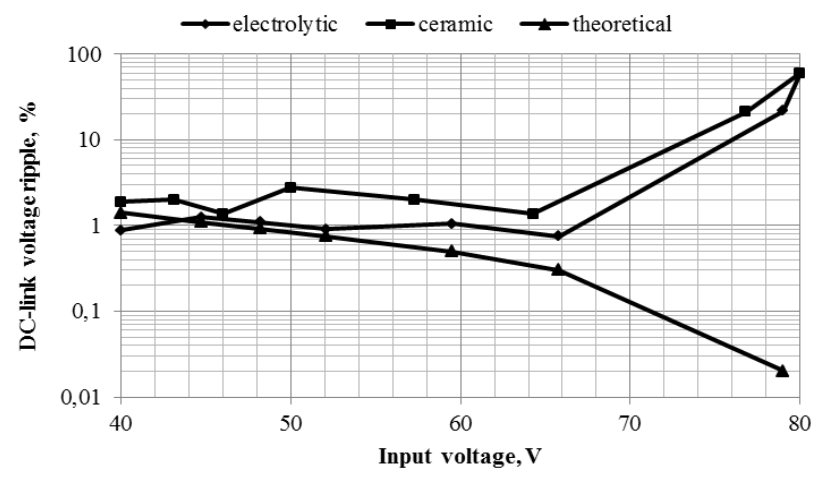

Fig. 9. Dependence of capacitor voltage ripple on the input voltage.

\section{COMPARISON OF POWER LOSSES}

Usually power losses can be associated with heat emission. Temperature measurements with thermal imager for both capacitor types were made after 2 minutes working. Fig. $10 a$ presents the case of minimal input voltage $\left(U_{I N}=40 \mathrm{~V}\right)$ and maximal shoot-through duty-cycle in order to obtain nominal voltage on the DC-link $\left(U_{D C}=80 \mathrm{~V}\right)$. Fig. $10 \mathrm{~b}$ shows the case of maximal input voltage $\left(U_{I N}=80 \mathrm{~V}\right)$ and minimal shootthrough duty-cycle.

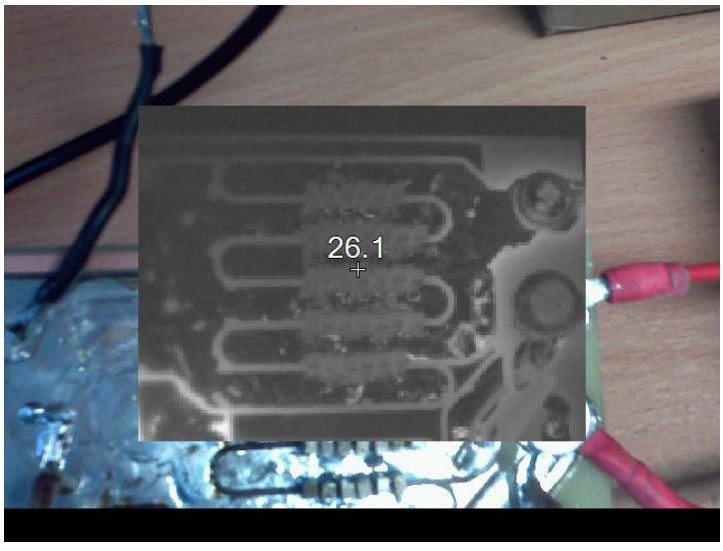

(b)

Fig. 10. Temperature measurement of ceramic capacitors: at minimal input voltage (40 V) (a) and at maximal input voltage ( $80 \mathrm{~V})$ (b).

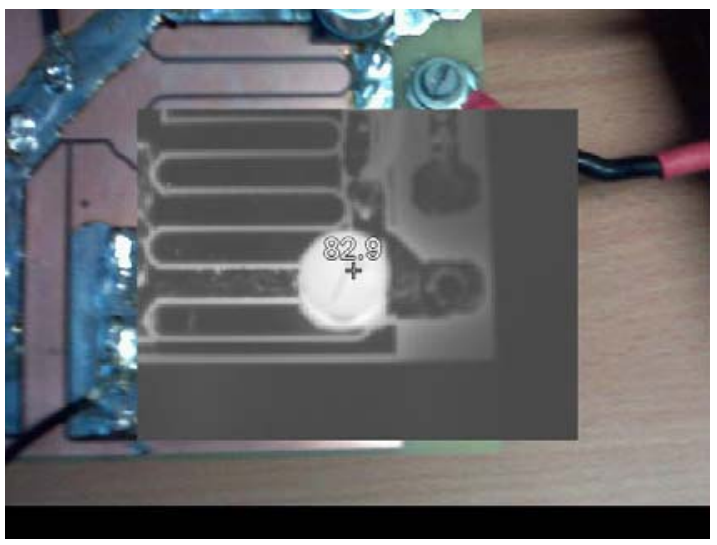

(a)

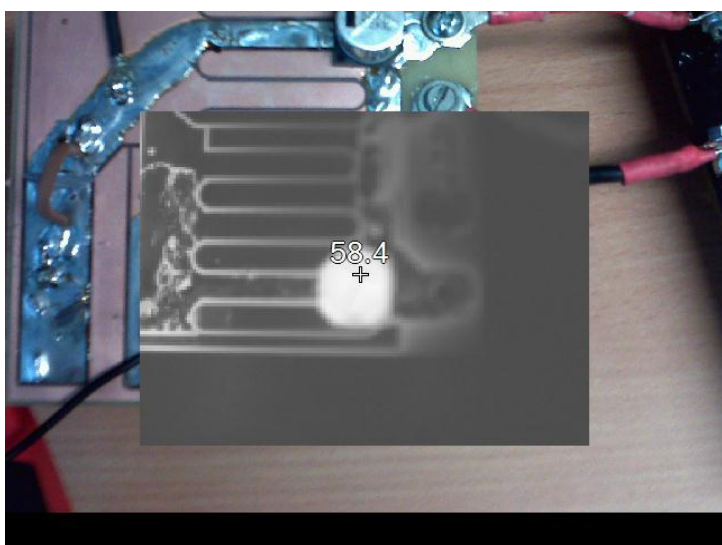

(b)

Fig. 11. Temperature measurement of electrolytic capacitors: at minimal input voltage (40 V) (a) and at maximal input voltage ( 80 V) (b). 
Fig. 11 shows the same measurement technique that was used for electrolytic capacitors.

It can be seen that the surface temperature of electrolytic capacitors (Fig. 11) is around two times higher than that of ceramic capacitors (Fig. 10) in both operation extremes (at minimal and nominal input voltage).

It can be explained by the facts from capacitor data sheets that the ESR of an electrolytic capacitor is given $0.75 \Omega$ (at $120 \mathrm{~Hz}$ ) but the ESR of one ceramic capacitor is around $3 \Omega$ (at $120 \mathrm{~Hz}$ ). But since the ceramic capacitor actually consists of 100 SMD ceramic capacitors soldered in parallel, actually $3 \Omega$ should be divided on 100 , thereby we obtain $0.03 \Omega$.

Generally, active power losses in capacitor can be expressed as

$$
P_{\text {loss }}=I_{C(R M S)}^{2} \cdot E S R
$$

where $I_{C(R M S)}$ is the RMS value of the capacitor current and ESR is equivalent series resistance.

In some cases there is given dissipation factor or loss tangent $(\tan \delta)$ and then power losses in capacitor can be expressed as

$$
P_{\text {loss }}=\frac{\tan \delta}{2 \cdot \pi \cdot f \cdot C} \cdot I_{C(R M S)}^{2} .
$$

Temperature rise of capacitor can be expressed as

$$
\Delta T=\left(T_{s}-T_{a}\right)=I_{C(R M S)}^{2} \cdot E S R \cdot R_{t h},
$$

where $T_{s}$ is surface temperature, $T_{a}$ is ambient temperature and $R_{t h}\left({ }^{\circ} \mathrm{C} / \mathrm{W}\right)$ is thermal resistance.

Usually ESR as well as impedance depending on the frequency are given in the capacitor data sheets.

Also very important fact that should be taken into account is ripple current. The data sheet of electrolytic capacitor says that ripple current at $100 \mathrm{kHz}$ should not exceed 0.9 A. Our experiments show that ripple current significantly exceed recommended. To check how this fact affect temperature raises it was decided to solder 2 additional capacitors in parallel with existing $C_{1}$ and 2 additional capacitors in parallel with existing $C_{2}$. The experiments showed that temperature of electrolytic capacitors didn't exceed $60^{\circ} \mathrm{C}$.

The difference between the temperatures in both operation extremes can be explained by twice higher input current in the minimal input voltage case.

\section{TECHNICAL-ECONOMICAL ANALYSIS}

It is essential to design and build a compact converter with high power density $[1,2]$. For that reason dimensions of the discussed capacitors are of essential importance to find the most effective placement. The total volume of one SMD electrolytic capacitor $(220 \mu \mathrm{F})$ is $4196.6 \mathrm{~mm}^{3}$, but the volume of one capacitor $(220 \mu \mathrm{F})$ that consists of 100 SMDs is $2187.5 \mathrm{~mm}^{3}$. The total volume of 100 ceramic capacitors is almost twice smaller than that of electrolytic capacitors, moreover, ceramic capacitors can be placed in a more flexible way because of their small dimensions.

\section{CONCLUSIONS}

This paper presents an experimental study of two SMD capacitor types - electrolytic and ceramic.

Operation waveforms in both input voltage extremes showed that no significant visual differences exist in the performance of the two types of capacitors.

Differences in voltage ripple were found in the electrolytic and ceramic capacitor case, especially in the capacitor $C_{2}$ case. This fact could be caused by high temperature on the electrolytic capacitors when the voltage ripple damping capability decreases. The heat reduction could be achieved by selecting capacitors with smaller impedance and higher permissible ripple current.

In terms of labour intensity, the mounting of electrolytic capacitors is much more convenient compared to ceramic capacitors.

It can be concluded that if labour intensity and price are not essential, then SMD ceramic capacitors can be recommended for high power applications. Electrolytic capacitors could be implemented only in the case of paralleling them in order to reduce total impedance.

\section{REFERENCES}

[1] J.W. Kolar, U. Drofenik, J. Biela, M.L. Heldwein, H. Ertl, T. Friedli, S.D. Round, " PWM Converter Power Density Barriers," presented at 7th Power Conversion Conference PCC '07, Nagoya, Japan 2007.

[2] F.H. Khan, L.M. Tolbert, "5 kW Multilevel DC-DC Converter for Hybrid Electric and Fuel Cell Automotive Applications," Industry Applications Conference, 42nd IAS Annual Meeting, pp.628-635, 23-27 Sept. 2007.

[3] Yuan Li; J. Anderson, F.Z. Peng, Dichen Liu, "Quasi-Z-Source Inverter for Photovoltaic Power Generation Systems," presented at 24th Applied Power Electronics Conference and Exposition, APEC 2009.

[4] D. Vinnikov, I. Roasto, J. Zakis, R. Strzelecki, "New Step-Up DC/DC Converter for Fuel Cell Powered Distributed Generation Systems: Some Design Guidelines". Journal "Electrical Review" ISSN 0033-2097, vol. 86, nr. 8, pp. 245-252, 2010.

[5] Murata ${ }^{\circledR}$ Technical Bulletin (online). Available: www.murata.com

[6] Panasonic $\AA$ Technical Bulletin (online). Available: www.panasonic.com
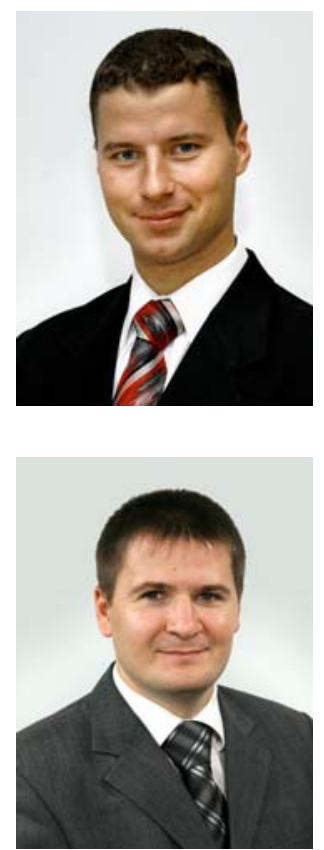

Janis Zakis (M'10) received B.Sc., M.Sc. and Dr.Sc.ing. in electrical engineering from Riga Technical University, Riga, Latvia, in 2002, 2004 and 2008, respectively. He is presently a Senior Researcher in the Department of Electrical Drives and Power Electronics, Tallinn University of Technology.

He has over 20 publications and is the holder of one Utility Model in power converter design. His research interests include flexible ac transmission systems, simulation of power systems, switching mode power converters, applied design of power converters.

Dmitri Vinnikov (M'07) received Dipl.Eng., M.Sc. and Dr.Sc.techn. in electrical engineering from Tallinn University of Technology, Tallinn, Estonia, in 1999, 2001 and 2005, respectively.

$\mathrm{He}$ is presently a Senior Researcher in the Department of Electrical Drives and Power Electronics, Tallinn University of Technology. He has authored more than 100 published papers on power converters design and development His research interests include switchmode power converters, modeling and simulation of power systems, applied design of power converters and control systems. 